\title{
chapter The Evolution of Psychiatric Practice in Britain
}

\author{
Allan Beveridge
}

\section{Introduction}

In 1960, the typical psychiatrist was male, white and British-born. He would spend most of his working day in a mental hospital. The majority of his patients would be compulsorily detained and many would have spent long periods incarcerated. ${ }^{1}$ He would not be a member of the Royal College of Psychiatrists as this organisation was not created until 1971. Instead, he would probably have attained a Diploma in Psychological Medicine (DPM) but would not have participated in a formal training scheme, as these did not exist either. ${ }^{2}$ In assessing his patients, he would have had a limited number of diagnoses at his disposal. Homosexuality was one of the diagnoses and he might use aversion therapy to treat the 'condition'. ${ }^{3} \mathrm{He}$ could prescribe antipsychotic medication, such as chlorpromazine and haloperidol, and antidepressants, such as imipramine, amitriptyline and phenelzine. He could also prescribe electroconvulsive therapy (ECT), though he might have to administer the anaesthetic himself. He could employ phenobarbitone and intramuscular paraldehyde for sedation, and he might resort to the use of the padded cell and the straitjacket, which were still available in some mental hospitals. He might have some expertise in psychodynamic psychotherapy, but this would depend on where he was working and whether the local psychiatric culture favoured such an approach. There was little in the way of specialisation, so he would be expected to deal with all the patients referred to him, the referrals coming almost exclusively from the general practitioner. At this time, the number of psychiatrists was small, and his contact with other colleagues outside his work would be at meetings of the Medico-Psychological Association (MPA) or in the pages of the Journal of Mental Science, the forerunner of the British Journal of Psychiatry, which was established in 1962.

By 2010, the typical psychiatrist was quite likely to be female and non-white, as, by this stage, many doctors had emigrated to Britain from the Indian subcontinent, Africa, the Caribbean and the Middle East. She would be working in a community resource centre or in a psychiatric unit in a district general hospital and most of her patients would be voluntary. She would receive referrals from not only general practitioners but also psychologists, social workers, occupational therapists, the police and other agencies. The range of problems she encountered was much larger than in 1960 and the expectation of cure or relief of symptoms was much higher. ${ }^{4}$ She would be a member of the Royal College of Psychiatrists, having passed her exams and participated in a training scheme, which involved rotating around the different psychiatric specialties. She would have access to many more diagnoses, some of them contentious, such as attention deficit hyperactivity disorder (ADHD), though homosexuality would no longer be considered a psychiatric condition. She would have a greater range of medications from which to choose, such as lithium and other mood stabilisers, 
though there had been no major breakthrough in psychopharmacology since the 1950s. She would be versed in psychodynamic psychotherapy, which was now a mandatory part of her training, and she would also be familiar with cognitive behavioural therapy and, perhaps, dialectical behavioural therapy and interpersonal therapy. The number of psychiatrists in Britain in 2010 was considerably larger than it had been in 1960, and there were now many specialties, such as addictions, psychotherapy, old age psychiatry, forensic psychiatry, liaison psychiatry, community psychiatry, intellectual disability psychiatry and rehabilitation. There were more conferences at which to meet colleagues, and the British Journal of Psychiatry had expanded to include other publications, such as the Psychiatric Bulletin, which focused on everyday clinical matters.

What sources are available to understand the day-to-day clinical experience of British psychiatrists during this period? As well as the secondary literature, there are witness seminars, ${ }^{5}$ where clinicians discuss past events. There are also various interviews with psychiatrists, but these tend to be focused on white men and on those who trained in London, more particularly at the Maudsley. ${ }^{6}$ It is difficult to discover what clinical life was like for women, though Angela Rouncefield, who worked in Liverpool in the 1960s, remembers that psychiatry, like the rest of medicine then, was very male-dominated and that she felt she was constantly having to prove herself. ${ }^{7}$ It is also difficult to find the testimonies of people from ethnic minorities and those working in the so-called periphery. There tends to be much more written about England than other parts of Britain. Andrew Scull has criticised this exclusively Anglocentric approach, which, although he was referring to Scotland, could equally apply to Wales and Northern Ireland:

With few exceptions, English-centred historiography ... largely neglected the very different Scottish approaches to the containment and treatment of the mad ... the scholarship of the time embodied the presumption (infuriating for the Scots, and typical of the English) that either the only thing that mattered was what occurred south of the border; or alternatively and without giving the matter much thought, what happened in England was also what occurred in politically subordinate Scotland. ${ }^{8}$

Within the limitations of the archival record, this chapter will attempt to examine the evolution of psychiatry between 1960 and 2010, as it was experienced by psychiatrists of the era.

\section{The Beginning of the Era}

In 2019, the social psychiatrist Tom Burns remembered the 1960s thus (see also Chapter 20):

in the late 60s, when I was doing this, psychiatry was ... quite prestigious. I mean nowadays it's all looked down on, psychiatry, it's a job that people who can't get proper medical jobs do. It wasn't like that then. It was the year of Ronnie Laing, and all that stuff, and but it was quite an exciting thing to do. And it did have its own glamour and prestige, you know, it wasn't seen as something that people who couldn't get other jobs did. ${ }^{9}$

\section{The Mental Hospital}

The old mental hospitals were still standing in 1960 but not all were the repressive institutions of folklore. Bill Boyd, who worked at Rosslynlee Hospital outside Edinburgh, remembers: 
It was very comforting and comfortable because Rosslynlee was still traditional under a very excellent and benign Physician Superintendent, Dr Andy Hegarty, I found I was accepted there very easily. There was a very informal, warm atmosphere amongst doctors, nurses and all the staff and there was a lot going on there too - out patient clinics in the local towns, patients coming up as day-patients, looking back now the services were remarkably advanced. ${ }^{10}$

In contrast, Hugh Freeman had more unpleasant memories:

My first experience of it, though, was as a locum at Wakefield, immediately before the Army. The neuroleptic era was just beginning then, but this mental hospital was quite Hogarthian in many ways, and some of the staff seemed to me as peculiar as the patients. When I first arrived there, on a misty January night, it was like the opening of a Hammer film. ${ }^{11}$

Malcolm Campbell, a neurologist, remembers his shock in the early 1960s when he started work at Friern Hospital, in London with its quarter-of-a-mile-long corridor providing the entrance to more than thirty wards, crammed with patients. ${ }^{12} \mathrm{~A}$ recent witness seminar demonstrated that the quality of mental hospitals varied greatly throughout the country, and there was a suggestion that the standard of care was higher in Scotland. ${ }^{13}$

Changes were afoot, however. The 1957 Report of the Royal Commission on the Law Relating to Mental Illness and Mental Deficiency (Percy Commission, 1957) was a crucial turning point in mental health policy in the UK. ${ }^{14}$ It urged relocating mental health care from hospital to community settings and inspired the 1959 Mental Health Act, which empowered local authorities in England and Wales to establish community mental health provision.

Psychiatrists tended to see the 1959 Act as benign in its impact on services and patient experience, partly because it allowed them, through the procedure of voluntary admission to mental hospitals, to implement improvements in treatment and care which had been foreshadowed in the 1950s. Services were dominated institutionally and intellectually by psychiatrists. ${ }^{15}$ Although the 1959 (England and Wales) and 1960 (Scotland) Acts differed in some respects, there were enough similarities between the two to anticipate that the drive in England and Wales to close down psychiatric hospitals would be mirrored north of the border. However, as Victoria Long has pointed out, the Scots were not as convinced as their English counterparts that psychiatric hospitals could be rapidly emptied of their patients. ${ }^{16}$

Bill Boyd remembers:

I was Chairman of the Scottish Division, we were accused in Scotland of not being as advanced as the south in terms of cutting back on beds and putting people into the community. I remember very clearly writing to the Scotsman on behalf of the Division pointing out that psychiatrists were at the forefront of developing Care in the Community but that we as a group were not prepared to put our patients out of hospital until we were confident that community facilities and indeed public attitudes had matured to a level where it was reasonable to move our patients into Community Care. ${ }^{17}$

\section{Rehabilitation}

During the 1970s, the numbers of patients in psychiatric hospitals fell. This was the era of 'deinstitutionalisation'. In 1970, Wing and Brown's classic Institutionalism and Schizophrenia was published. ${ }^{18}$ The authors compared three psychiatric hospitals and found that the social 
environment had a considerable effect on the mental state of the patients. The more deprived the environment, the worse the outcome. However, too much stimulation could also have adverse effects on the patients as well. The London social psychiatrist, Jim Birley, maintained that the goal of rehabilitation was to find the appropriate level for each patient. ${ }^{19}$ Diagnosis was not so important in predicting outcome for these patients. Developing living skills was more important, and here clinical psychologists and occupational therapists played a crucial part, while Industrial Rehabilitation Units helped patients get back into the way of work. However, Birley conceded that the early optimistic belief that patients could become independent was not borne out by experience. There was the danger of what he termed 'transinstitutionalisation', whereby patients were merely transferred from hospital to other deprived environments, such as boarding houses, nursing homes or the street. In addition, after the 1960s employment fell and it was less easy for the mentally ill to find jobs.

Birley also felt that many psychiatrists were not particularly interested in looking after the long-term mentally ill. By 1970, many acute psychiatric units had been built in general hospitals, and these proved more attractive to psychiatrists. Birley observed:

Psychiatrists, like most doctors, prefer to look after patients who get better ... Psychiatric departments of medical schools, where most psychiatrists were trained, felt that they required a regular supply of acute and preferably 'new' cases for teaching. ${ }^{20}$

As a result, many psychiatrists had not been trained in the management of the chronically mentally ill, whom, Birley maintained, they often perceived as unattractive in appearance, behaviour and level of hygiene. In addition, many psychiatrists felt vulnerable outside the hospital, working with different staff with different approaches, though some greatly enjoyed it.

As well as the efforts to move the long-term psychiatric residents outside asylum walls, there was the movement to treat patients in the community, known as social or community psychiatry. As Tom Burns recalled, the flagship of social psychiatry was the therapeutic community movement, which encompassed Fulbourn, Napsbury, Dingleton and Henderson Hospitals. $^{21}$ Although a pioneer and an enthusiast, he recognised some of the difficulties:

You're stripped of the normal paraphernalia of status. You know, you've got an outpatient clinic in medicine, there are receptionists and nurses and medical students and being a consultant is good for your ego, you know, you're the expert that everything circles around. If you do social psychiatry, it's you and perhaps one of your colleagues, a nurse or social worker, plus the patient and their family on their territory.

... when I look back on it, the, particularly when social psychiatry started to move out more and more into sort of community-based work and stripping away all these structures that we normally relied on, I, I think we probably underestimated how important they are to sustain people in difficult jobs ... So, I think one thing that we've gotten wrong a bit was that we turned our back a little bit too much on the benefits of institutional care. I mean, not for the patients, but for us. ${ }^{22}$

The lack of sufficient resources for community care of the mentally ill was already causing frustration to clinicians. ${ }^{23}$

\section{Other Developments}

Hugh Freeman recalled: 'there was no tradition of multidisciplinary team working; that was one of the achievements of our efforts in the ' $60 \mathrm{~s}^{\prime},{ }^{24}$ a sentiment which David 
Goldberg also expressed. ${ }^{25}$ Tom Burns felt that the sectorisation of psychiatric services into geographical 'catchment areas' which began in the 1960s was a major and valuable development. $^{26}$

Further, as Turner (see also Chapter 23) and colleagues observed:

The 1970s also saw significant innovations in treatment and service delivery, led by clinicians responding to these challenges. There was increasing use of psychological treatments with an evidence base and widespread acceptance that the services needed to acknowledge and counteract the social devaluation of their users. ${ }^{27}$

With the rundown of the old mental hospitals, came the setting up of psychiatric units in general hospitals. The advocates claimed they would lead to a reduction of stigma, greater accessibility for patients and a closer alliance between psychiatry and general medicine, leading to improvements in the patients' physical health. ${ }^{28}$ For many psychiatrists, it was a great step forward. Maurice Silverman, working at Blackburn commented:

I think the basic difference is that in the DGH [district general hospital] unit, as a psychiatrist, you have a very much more intimate relationship with other personnel and with the surrounding community. Under 'other personnel', I'm including other consultants in every specialty, the GPs in the area, and community social workers. ${ }^{29}$

Others, though, were less keen. Thomas Freeman, who worked at Gartnavel Royal in Glasgow, commented:

I was perhaps going to swim against the tide as by 1963-1964 there was already talk of the mental hospital becoming superfluous. Hope was now pinned on the new medications and on the psychiatric unit of the general hospital. I strenuously opposed this, pointing to the fact that as yet we were without aetiologically based treatments. Chronically ill patients would remain with us; where else were they to go? Today we have the legacy of these optimistic forecasts and the actions which were based on them. ${ }^{30}$

Professor Elaine Murphy (see also Chapter 12) also complained:

Psychiatrists pressed for more convenient and congenial facilities in DGHs - the time spent with the long-term patients decreased in asylums and in the community. By the time the Royal College of Psychiatrists was established in 1971, training was focused on short term and emergencies. ${ }^{31}$

Murphy contended that there had emerged a two-tier system in England, with the new DGHs and the old, less well-funded asylums. Goldberg objected to the practice at the Maudsley of sending their seriously mentally ill patients, who had relapsed, to local mental hospitals. $^{32}$

There were significant differences, however, between England and Scotland in their attitude towards psychiatric units sited in general hospitals. According to Long:

[Health] Departmental officials in Scotland believed that general hospitals lacked a number of resources specially designed to assist psychiatric patients, and favoured upgrading mental hospital care by using the small drop in inpatient numbers to relieve overcrowding and close down wards in old, obsolete buildings. Psychiatric units in general hospitals, they believed, should not be developed at the expense of existing mental hospitals, and efforts 
should be made to integrate the two forms of provision to stop a two-tier service developing. ${ }^{33}$

\section{The Royal College of Psychiatrists and the Development of Specialties}

The Royal College of Psychiatrists was founded in 1971. As Bewley shows, the path to its establishment was tortuous and many psychiatrists as well as doctors from other disciplines opposed it. ${ }^{34}$ Trainee psychiatrists, who were worried about the entrance requirement of a formal examination, campaigned successfully for the provision of adequate ongoing education before they were expected to sit such an exam. Hugh Freeman discussed the lack of formal training before the advent of the College:

At that time, the psychiatric profession here was very small, compared with today, and the greater part of it consisted of doctors who had grown-up in mental hospitals under the apprenticeship tradition. There was very little alternative to that, as the Universities and teaching hospitals provided only very few places indeed for those who wanted to train in psychiatry. ${ }^{35}$

The period witnessed the growth of a rapidly ageing population - by 1990, half of all long-stay beds were occupied by old people with dementia. ${ }^{36}$ The response was the development of the psychiatric care of the elderly, which had its origins in the late 1960s (see also Chapter 22). ${ }^{37}$ R. A. Robinson at the Crichton Royal Hospital in Dumfries was an early pioneer. In 1970, the government urged that psychogeriatric assessment units should be set up in general hospitals. According to Arie and Jolley, ${ }^{38}$ the main progress was in the development of services and they contended that the emphasis on bringing treatment to the patient's home led the way for the rest of psychiatry. Further, the links with medicine contributed to the reintegration of psychiatry into medicine, at least to some extent.

Following the 1959 Mental Health Act in England and Wales, there was a reduction in the number of locked wards in psychiatric hospitals. ${ }^{39}$ In the early 1970s, there were only eight forensic psychiatrists in England (see also Chapter 29). Following the Butler Report in 1975, there were more than 150 consultants. When he was interviewed in 1990, the Edinburgh forensic psychiatrist Derek Chiswick said:

Forty years ago a handful of forensic psychiatrists spent their time giving evidence in the various 'hanging' trials ... which decided whether a murderer was to live or die. Today the picture has changed. Forensic psychiatrists are fully involved in both assessment and treatment (the latter very important) of a wide range of mentally abnormal offenders ... You will find forensic psychiatrists in various clinical settings including the maximum security or special hospitals (of which there are five in Britain), in the new regional secure units which have developed in England (though not in Scotland), in ordinary psychiatric hospitals and clinics, and also visiting psychiatrists to prisons. ${ }^{40}$

However, in the 1980s, following the killing of a social worker by a mentally ill individual, it became mandatory in England to set up a homicide inquiry if a mentally ill person committed a murder. As a result, all English psychiatrists, and, indeed, all mental health workers, practised within a 'blame culture' setting, and this culture was also apparent, albeit to a lesser degree, in Scotland, though it did not have the same mechanism of automatic inquiries (see also Chapters 8 and 28). 
Dr Max Glatt inaugurated the first unit for alcoholism at a mental hospital in Britain in 1951; between then and 1973, more than twenty such units were established by the NHS (see also Chapter 25). ${ }^{41}$ However, research in the 1970 s cast doubt on this approach, demonstrating that many could be improved by outpatient treatment alone or brief interventions.

Bruce Ritson describes how the approach to alcohol problems evolved during this period:

A strongly held view at that time was that people who were alcoholic had become so because of some underlying psychological problem. The emphasis - and this is what attracted me in the first place - was on finding out what the psychodynamics of their particular addiction were and then trying to help, usually with group psychotherapy and sometimes with individual psychotherapy or couple therapy. The focus was on finding an underlying psychic cause, which I do not think I would really go along with now. Sometimes there is an underlying cause, but often it is the outcome of chronic exposure to excessive drinking and the psychological harm is secondary. ${ }^{42}$

There was a long-running campaign to persuade the College to accept that training in psychotherapy should be an integral part of the training of general psychiatrists. Heinz Wolff, a psychotherapist at University College London, observed:

I recall how hard we had to fight to have the first Guidelines for the Training in Psychotherapy accepted by the Council and other committees in 1971. For me it was less important exactly what the guidelines said but rather that the College should acknowledge the importance of training of psychiatric trainees in dynamic psychotherapy. ${ }^{43}$

In 1993, the College published guidelines making training in psychotherapy a mandatory requirement for qualification as a psychiatrist. ${ }^{44}$

Until the 1970s, dedicated liaison services were virtually unknown in Britain. A special interest group in liaison psychiatry was set up in the early $1980 \mathrm{~s}^{45}$ The specialties of intellectual disability, child psychiatry and others also evolved during this period.

\section{Crisis of Confidence among Psychiatrists}

The advent of the Conservative government in 1979 saw the rapid development of the New Right, which explicitly encouraged both privatisation and competition. The first service user movements appeared in the early 1970s, demanding civil and economic rights for patients in the community, and, in parallel, pressure groups such as Mind began to agitate for changes to the 1959 Act (see also Chapters 13 and 14). ${ }^{46}$ In Psychiatry in Dissent, published in 1980, Clare judged that contemporary psychiatry was in an unhealthy state, with problems of recruitment, lack of resources and its lowly status in the medical hierarchy. ${ }^{47}$ Writing in 1983, Sedgwick delineated many of the circumstances that undermined the authority of psychiatrists. ${ }^{48}$ He noted the failure to accept psychiatric expertise in the legal courts following the Peter Sutcliffe trial, the popularity of anti-psychiatric arguments and the collusion of this attitude with the political 'New Right'. An editorial in 1985 in the Lancet claimed that psychiatry was a 'discipline that had lost its way'. ${ }^{49}$ In 1986 , Bhugra reported on the largely negative public perception of psychiatry. ${ }^{50}$

Writing in 1989, Tom Harrison, a psychiatrist from Birmingham, reported on the concerns of his consultant colleagues: ${ }^{51}$ 
First is the declining morale of the psychiatrist and second are the rising expectations of other mental health workers ... Other professions in mental health have been influenced by a number of factors. These include: a broadening knowledge base and range of skills, increasing specialisation, more graduate nursing recruits, less acceptance of authoritarian management, often accompanied by idealistic enthusiasm, and increasing independence of operation with less direct supervision.

More generally, Hugh Freeman lamented:

The NHS was one of the best things that ever happened in Britain. I find that the shift in the philosophy of the service is, with a widespread loss of idealism and commitment, the most disturbing change of all. It derives mainly from the domination by managers and accountants, who seem to have no personal concern with the objectives of a Health Service, but of course, it's also part of a general cultural shift away from the liberalism and sense of community of the post-war period. ${ }^{52}$

Psychiatry found itself criticised by patients, relatives, anti-psychiatrists and other mental health professionals. Birley observed:

Psychiatrists responded to these criticisms ... in various ways. A positive approach was to view critics as potential allies ... Another reaction was to strive to make psychiatry more scientific ... but turning to medical science was liable to omit the social and behavioural disciplines. $^{53}$

According to Rogers and Pilgrim, these opposing attitudes have continued into the twentyfirst century (see also Chapters 5 and 20). ${ }^{54}$ In a paper in the British Journal of Psychiatry in 2008, Craddock and his colleagues warned:

British psychiatry faces an identity crisis. A major contributory factor has been the recent trend to downgrade the importance of the core aspects of medical care ... Our contention is that this creeping devaluation of medicine is damaging our ability to deliver excellent psychiatric care. It is imperative that we specify clearly the key role of psychiatrists in the management of people with mental illnesses. ${ }^{55}$

In response, Bracken and his colleagues countered by arguing that a rigid adherence to the medical model was inappropriate in treating mental illness, and, instead, they favoured an approach which focused on an understanding of the social and existential aspects of the patient. $^{56}$

\section{Conclusion}

At the beginning of this chapter, the clinical world of the psychiatrist in 1960 was contrasted with that of his counterpart in 2010. It would be facile to view the changes in psychiatry during this period as one of straightforward progress. Certainly, there were many improvements. The old asylums, many of which were overcrowded and untherapeutic, were largely closed or had their bed numbers reduced and more patients were now cared for in the community. The patient's voice was more likely to be heard and attended to than in the past. A witness seminar for English mental health workers concluded: 'that one of the most important and striking changes in the history of post-war British mental health care has been the rise of the service user perspective'. ${ }^{57}$ There were now more psychiatrists and they came from more diverse backgrounds than before, with many more women in the profession. However, morale had 
declined, though personal experience and anecdotal evidence suggest that this was less so in Scotland. There was disagreement as to whether psychiatry should be seen primarily as a branch of medicine or whether it should be more concerned with the psychological and social aspects of patients' distress. Roy Porter noted a paradox: while psychiatry had reformed its old institutions and now offered a wider range of therapies, the general public had responded with a resurgence of suspicion and lack of confidence in psychiatrists. ${ }^{58}$

\section{Key Summary Points}

- The era saw the gradual closure of the mental hospitals and the development of care in the community - a process known as 'deinstitutionalisation'.

- Community care revealed its own problems: some patients were merely transferred to different kinds of institution; there was a lack of funding; and there was an unease among some psychiatrists at working outside the hospital.

- There was the innovative development of multidisciplinary teams; sectorisation; and district general hospitals (DGHs).

- The Royal College of Psychiatrists was founded in 1971, leading to formal education schemes for trainees and the creation of psychiatric specialties.

- The psychiatric profession underwent a crisis of confidence as a result of several factors: the increasing privatisation of the health service; the challenge to its authority from both other mental health professionals and the emerging service user movement; and problems with recruitment.

\section{Acknowledgements}

Thanks to Nicol Ferrier, Femi Oyebode and Bruce Ritson for their helpful comments and advice with this chapter.

\section{Notes}

1. J. Turner, R. Hayward, K. Angel et al., The history of mental health services in modern England: Practitioner memories and the direction of future research. Medical History (2015) 59(4): 599-624.

2. M. Shepherd and D. Watt, In M. Shepherd, ed., Psychiatrists on Psychiatry, 185-203. Cambridge: Cambridge University Press, 1982.

3. R. Davidson, Psychiatry and homosexuality in mid-twentieth century Edinburgh: The view from Jordanburn Nerve Hospital. History of Psychiatry (2009) 29(4): 403-24.

4. Turner, Hayward, Angel et al., The history of mental health services in modern England.

5. C. Hilton and T. Stephenson, eds, Psychiatric Hospitals in the UK in the 1960s [Witness Seminar]. London: RCPsych Publications, 2020.

6. G. Wilkinson, ed., Talking about Psychiatry. London: Gaskell, 1993.

7. Hilton and Stephenson, Psychiatric Hospitals.

8. A. Scull, The peculiarities of the Scots? Scottish influences on the development of English psychiatry, 1700-1980. History of Psychiatry (2011) 22(4): 403-15.

9. M. Smith (Creator) (8 August 2019). Social Psychiatry Oral History Interviews. University of Strathclyde. Transcripts (zip).10.15129/7ada.0b9e-98eb-429d-98ac-486413ecf36a. Tom Burns. Interviewed by Linsey Robb. 11 May 2015. 
10. B. Boyd. In conversation with David Tait. Psychological Bulletin (1997) 21: 769-74.

11. G. Wilkinson, In conversation with Hugh Freeman. Psychological Bulletin (1993) 17: 388-404.

12. Hilton and Stephenson, Psychiatric Hospitals.

13. Ibid.

14. V. Long, 'Heading up a blind alley'? Scottish psychiatric hospitals in the era of deinstitutionalization. History of Psychology (2017) 28(1): 115-28.

15. Turner, Hayward, Angel et al., The history of mental health services in modern England.

16. Long, 'Heading up a blind alley?'.

17. Boyd, In conversation with David Tait.

18. J. K. Wing and G. W. Brown, Institutionalism and Schizophrenia. Cambridge: Cambridge University Press, 1970.

19. J. Birley. Rehabilitation. In H. Freeman, ed., A Century of Psychiatry, 253-6. London: Mosby, 1999.

20. Ibid.

21. Smith, Social Psychiatry Oral History Interviews.

22. Ibid.

23. Turner, Hayward, Angel et al., The history of mental health services in modern England.

24. Wilkinson, In conversation with Hugh Freeman.

25. Hilton and Stephenson, Psychiatric Hospitals.

26. T. Burns, Our Necessary Shadow: The Nature and Meaning of Psychiatry. London: Allen Lane, 2013.

27. Turner, Hayward, Angel et al., The history of mental health services in modern England.

28. A. Clare, Psychiatry in Dissent: Controversial Issues in Thought and Practice (2nd ed.). London: Routledge, 1980.

29. H. Freeman, In conversation with Maurice Silverman. Psychological Bulletin (1992) 16: 385-90.

30. Perspective. Thomas Freeman. Psychological Bulletin (1988) 12: 306-9.

31. E. Murphy, After the Asylums: Community Care for People with Mental Illness. London: Faber \& Faber, 1991.

32. Hilton and Stephenson, Psychiatric Hospitals.

33. Long, 'Heading up a blind alley?'.

34. T. Bewley, Madness to Mental Illness: A History of the Royal College of Psychiatrists. London: RCPsych Publications, 2008.

35. Wilkinson, In conversation with Hugh Freeman.

36. Murphy, After the Asylums.

37. T. Arie and D. Jolley, Psychogeriatrics. In Freeman, A Century of Psychiatry, 260-4.

38. Ibid.

39. P. Snowden and H. Freeman, Forensic Psychiatry. In Freeman, A Century of Psychiatry, 265-9.

40. D. Chiswick, Conversation piece: The forensic psychiatrist. Postgraduate Medical Journal (1990) 66: 68-9.

41. B. Ritson, Alcoholism. In Freeman, A Century of Psychiatry, 218-22.

42. Conversation with Bruce Ritson. Addiction (2010) 105: 1346-54.

43. S. Bloch, In conversation with Heinz Wolff: Part 2. Psychological Bulletin (1989) 13, 337-42.

44. J. Holmes, The integration of psychiatry and psychotherapy. Psychological Bulletin (1995) 19: 465-6. 
45. P. Aitken, G. Lloyd, R. Mayou et al., A history of liaison psychiatry in the UK. Psychological Bulletin (2016) 40 (4): 199-203.

46. Turner, Hayward, Angel et al., The history of mental health services in modern England.

47. Clare, Psychiatry in Dissent.

48. P. Sedgwick, The fate of psychiatry in the new populism. Psychological Bulletin (1983) 7: 22-5.

49. Anon. Psychiatry: A discipline that has lost its way. The Lancet (1985) 325: 731-2.

50. D. Bhugra, The public image of psychiatry. Psychological Bulletin (1987) 11: 105.

51. T. Harrison, The role of the consultant psychiatrist in the clinical team. Psychological Bulletin (1989) 13: 347-50.

52. Wilkinson, In conversation with Hugh Freeman.

53. Birley, Rehabilitation.

54. A. Rogers and D. Pilgrim, A Sociology of Mental Health and Illness (5th ed.). Maidenhead: Open University Press, 2014.

55. N. Craddock, D. Antebi, M.-J. Attenburrow et al., Wake up call for British psychiatry. British Journal of Psychiatry (2008) 193: 6-9.

56. P. Bracken, P. Thomas, S. Timimi et al., Psychiatry beyond the current paradigm. British Journal of Psychiatry (2012) 201: 430-4.

57. Turner, Hayward, Angel et al., The history of mental health services in modern England.

58. R. Porter, Two cheers for psychiatry! The social history of mental disorder in twentieth century Britain. In H. Freeman and G. E. Berrios, eds, 150 Years of British Psychiatry, Volume 2: The Aftermath, 383-406. London: Athlone Press, 1996. 